\title{
AN EXPLICIT BOUND FOR THE ERROR TERM OF THE DEVELOPMENT AT $s=1$ OF A SET OF LACUNARY SERIES
}

\section{GIUSEPPE MOLTENI} Abstract. An explicit bound for the error term of the expansion of $F_{n}(x):=\sum_{k=0}^{\infty} k^{n} x^{2^{k}}$ as
$x \rightarrow 1^{-}$is given.

Mathematics subject classification (2000): 33E20.

Key words and phrases: Lacunary series.

\section{REFERENCES}

[1] P. Boldi AND S. Vigna, Codes for The Word-Wide Web, Internet Math. 2 (2005), no. 4, 407-429.

[2] The Webgraph Framework I: Compression Techniques, Proc. of the Thirteenth International World Wide Web Conference (Manhattan, USA), ACM Press, 2004, pp. 595-601.

[3] T. J. BRomwich, An introduction to the theory of infinite series, 3rd ed., Chelsea, New York, 1991.

[4] H. Delange, Sur les zéros réels des polynômes de Bernoulli, C. R. Acad. Sci. Paris Sér. I Math. 303 (1986), no. 12, 539-542.

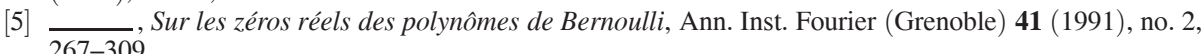
267-309.

[6] D. H. LeHMER, On the maxima and minima of Bernoulli polynomials, Amer. Math. Monthly 47 (1940), 533-538.

[7] L.LovÁsz, Combinatorial problems and exercises, second ed., North-Holland Publishing Co., Amsterdam, 1993.

[8] S. Roman, The umbral calculus, Pure and Applied Mathematics, vol. 111, Academic Press Inc., New York, 1984.

[9] G. TENENBAUM, Introduction to analytic and probabilistic number theory, Cambridge Studies in Advanced Mathematics, vol. 46, Cambridge University Press, Cambridge, 1995, Translated from the second French edition (1995) by C. B. Thomas. 